\title{
تطبيق طريقة القراءة السريعة فى تعليم مهارة القراءة للبنات \\ بمعهد دار الأبرار بونى
}

Mardhiana Jamal

STAI AL GAZALI

(Dhianjamal6@gmail.com)

\section{Kata Kunci:}

Keterampilan

membaca

Metode quantum reading
هذ البحث يبحث عن تطبيق طريقة القراءة السريعة (Quantum Reading) فى تعليم مهارة القراءة صف الحادى عشر للبنات بمعهل دار الوبرار بونى. وتستخدم الباحثة منهجا وصفيا على الملمخل الكيفي، بطريقتين لأدوات البحث هما: الملاحظة والمقابلة. وأما المشكلة التى تواجهها الطالبات فلمات في تعليم مهارة

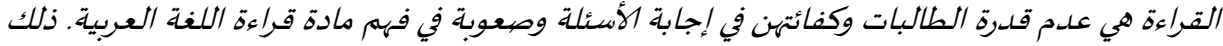

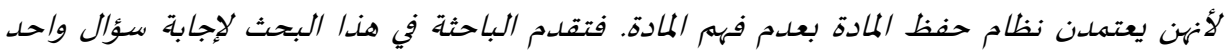
هي:كيف تطبيق طريقة القراءة السريعة فى تعليم مهارة القراءة صف الحادى عشر للبنات بمعهد دار

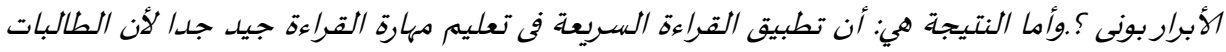

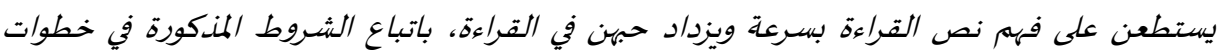
تطبيق القراءة السريعة.

\section{ABSTRAK}

Penelitian ini membahas tentang Penerapan Metode Quantum Reading dalam Pembelajaran Keterampilan Membaca Kelas Sebelas Putri di Pondok Pesantren Darul Abrar Bone. Adapun permasalahan yang dihadapi oleh siswa dalam keterampilan membaca adalah kurangnya kemampuan siswa dan kompetensi mereka untuk menjawab pertanyaan dan kesulitan dalam memahami materi membaca bahasa Arab. Itu disebabkan karena mereka mengandalkan hafalan tanpa memahami materi. Hadirnya penelitian ini untuk menjawab satu pertanyaan yaitu: bagaimana penerapan metode quantum reading dalam pembelajaran keterampilan membaca kelas sebelas putri di pondok pesantren Darul Abrar Bone?. Hasil dari penelitian ini adalah: penerapan metode quantum reading dalam pembelajaran keterampilan membaca kelas sebelas putri di pondok pesantren Darul Abrar Bone sangat baik karena siswa mampu memahami teks bacaan dengan cepat dan meningkatkan cinta mereka dalam membaca, dengan syarat mengikuti langkah-langkah yang telah disebutkan dalam penerapan metode Quantum Reading.

Mardhiana Jamal

تطبيق طريقة القراءة السريعة في تعليم مهارة القراءة صف الحادى

ALSUNA Vol. 1 (1), 2018 
أول آية من القرآن نزلت على أشرف الأنبياء والمرسلين محمد صلى الله عليه وسلم هي سورة العلق. هذه الآيات الكريمة وما بعدها سميت سورة العلق أو سورة إقرأ لأن الله سبحانه وتعالى افتتحها بكلمة

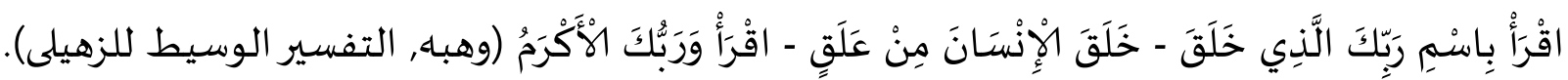

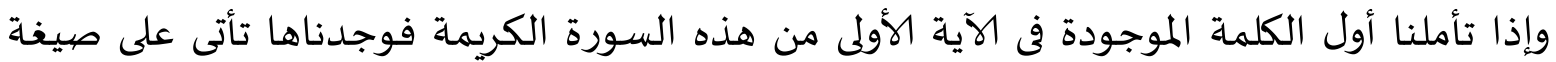

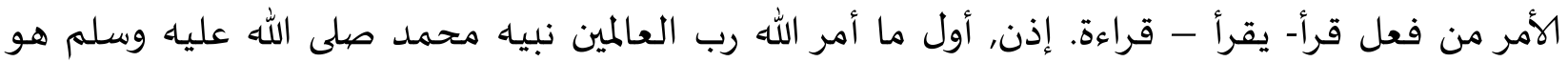

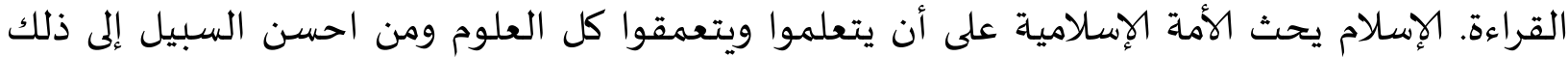

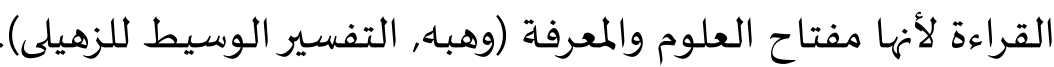

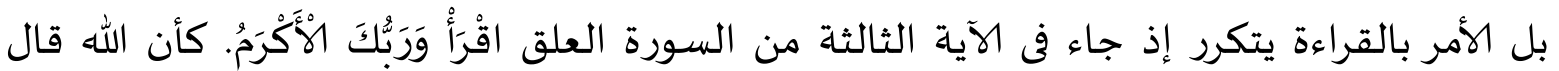

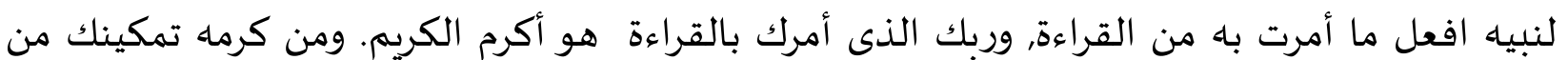

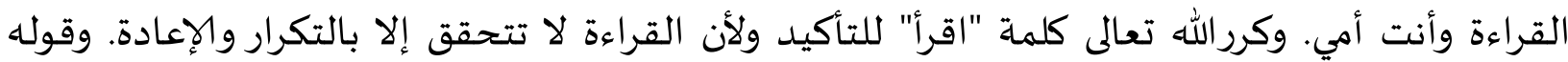

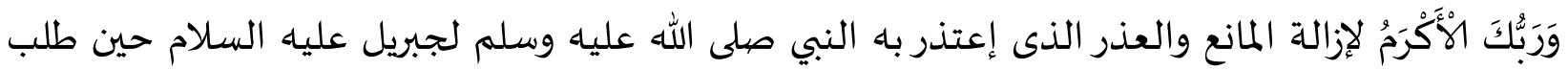
منه القراءة بقوله اقرأ فقال ما أنا بقارئ, أي لست متعلما بالقراءة. فالكتابة قيد العلوم والمعارف ووسيلة ضبط أخبار الأولين ومقالاتهم وأداة انتقال العلوم بين الأمم والشعوب, فتبقى المعلومات ثم يبنى عليها ويزاد إلى ما شـاء الله فتنمو الحضارات وتسمو الأفكار وتحفظ الأديان وتنشر الهداية, وجاء في الأثر "قيدوا العلم بالكتابة" (وهباه, التفسير المنير في العقيدة والشريعة

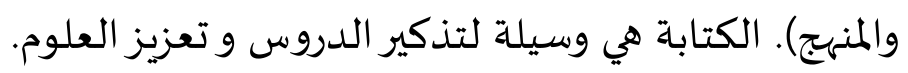
اللغة آلة اتصالية هامة بين الناس في شتى جوانب حياتهم فلن تصلح أمور حياتهم دون اللغة لعدم توفر الاتصال ـ والقراءة مهارة من المهارات اللغوية لا بد منها عند تعليم أي اللغات العالمية. اللغة الإنسانية

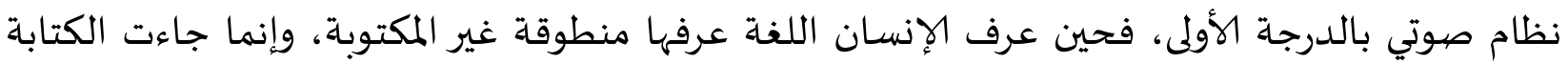

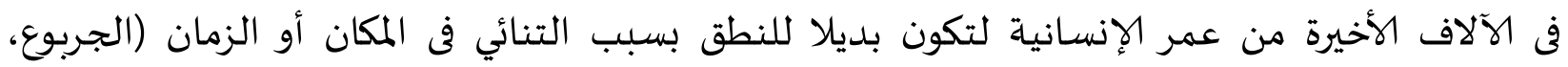

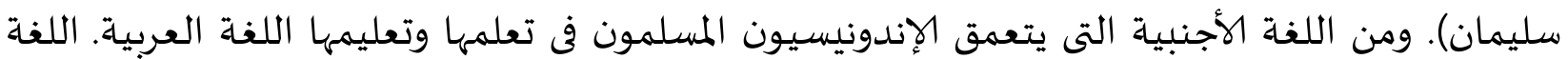
العربية هي الكلمات التى يعبر بها العرب عن أغراضهم (مصطفى). القراءة مفتاح من مفاتيح المعرفة وهي

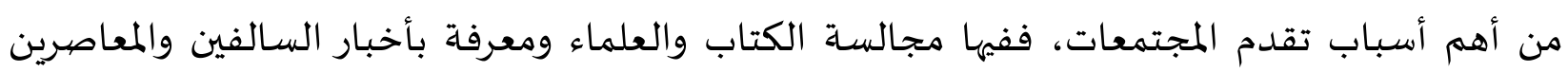

$$
\text { وعلومهم(الفوزان، عبد الرحمن). }
$$

ومن الدليل إلى الظروف، كان تدريس اللغة العربية في المدارس أو الجامعات يتركز في القواعد النحوية والصيغ الصرفية، حتى يجرى التعليم مملا لدى التلاميذ وغير جذابة نحوهم ولا يجلب ميولهه إلى تعلمها واستيعابها حتى لا يستطيعوا الاتصالات العربية بينهم ولو كانوا قد تعلموها عدة سنوات. والأهم في 
التدريس -لا سيما مادة اللغة- إشتراك التلاميذ حتى يتساهموا فى إيجاد الظروف الحية المتفاعلة الجيدة فى الفصل الذى تجرى فيه عملية التعليم (إفندى). إذا قارنا اللغة العبية بغيرها من اللغات الإنسانية، كانت اللغة العربية مواد متنوعة، بداية من تلفظ حروفها أو مخارج الحروف وقواعدها والتغيير في إعرابها واشتقاقها والمذكر والمؤنث وما إلى ذلك. كثير من التلاميذ يشعرون بأن تعلم اللغة العربية أكثر صعوبة مما كانوا عليه في تعلم لغة أجنبية أخرى إنها

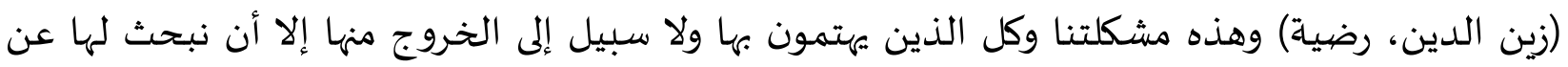

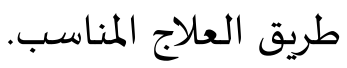
ومن المشكلة التى تواجهها الطالبات فى تعليم مهارة القراءة هي عدم قدرة الطالبات وكفائهن في

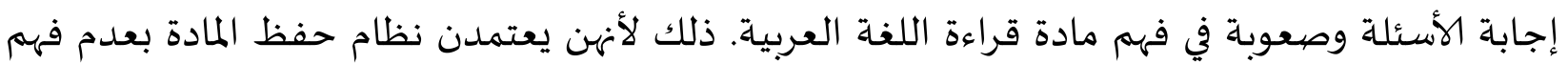

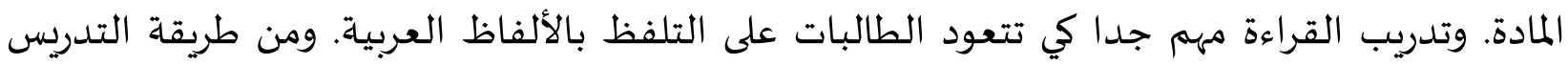

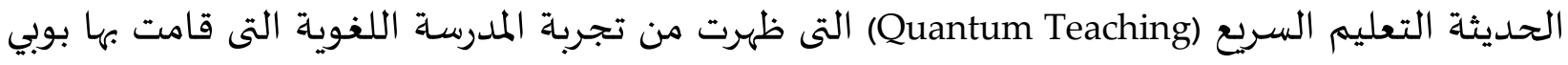
ديفرتير وجائت أيضا بالطريقة الجديدة في مجال القراءة تسهى القراءة السريعة ) De Porter, Quantum (Learning, Unleashing The Genius In You انطلاقا من تلك المقدمة فتقدم الباحثة في هذا البحث لإجابة سؤال واحد: ا.كيف تطبيق طريقة القراءة السريعة في تعليم مهارة القراءة صف الحادى عشر للبنات بمعهد

$$
\text { دار الأبرار بونى ؟ }
$$

\section{الدراسة النظرية}

القراءة السريعة، السريعة فى مجال علم فيزيا هو التعامل الذى يغير القوة إلى النور ( De Porter, Quantum Learning, Unleashing The Genius In You الدرس الذى يغير كل القدرات الإنسانية المؤثرة فى الحصول على أشياء جديدة، وهذه العملية تنضم إليها القراءة (Herwono). القراءة السريعة توحد الميول المرتفعة والتركيز الموجاه وستراتيجية القراءة المعينة وتنتفع من قدرة المخ على التقاط عدة الكلمات فى وقت واحد. هناك خمس الخطوات السهلة تدريبا على القراءة السريعة، منها:

$$
\text { 1. اليكون القارئ مريد المعرفة }
$$


القراءة السريعة بالنسبة للقارئ تطرح له الأسئلة قبل ان يقوم بعملية القراءة، منها: عما يقرأ؟. أي المنفعة التى يريد الحصول عليها؟. كيف يستطيع أن يستخدم هذا الإعلام؟. ثم ليرفع القارئ ميوله بإتيان لنفسه الدوافع إلى القراءة، لأن المخ الذكي لا يزال يريد معرفة كل شيئ. r. ليدخل القارئ إلى حال التركيز الموجه إن القراءة السريعة تطلب التركيز المرتفع. تحضيرا على التركيز ليجلس القارئ مستقيما ويغمض عينيه ويتنفس أطول ما يمكن. ثم يفكر مكانا آمنا مسرا له زاره أو ما سبق له من له التدريب ويحرك كرة عينيه ثم يفتحهما وأخيرا ينظر إلى الكتاب. ب. - م. النظر مجملا إلى الصفحة بعد التركيز الموجاه، يبدأ القارئ النظر الكتاب الذى سيقرأه مجملا سريعا وهذا يراد باه القراءة السعرى. ينظر القارئ صفحة كلها في الوقت ذاته بتحريك أصابعه التى تنزل من أعلى الصفحة إلى أسفلها ويتبعها النظر الذى يبحث عن شيئ بارز كعنوان الباب والكتابة الغليظة والصورة والجدول والأسئلة اللاحقة في آخر الباب.

ليقوم القارئ بهذا النشاط مرات حصولا على ما يحتوى الكتاب الرئيسي, وعندما يبدأ القراءة يفعلها بسرعة ويدرك فهما جيدا. وأثناء النظر المجمل إلى الكتاب ليسئل القارئ نفسه أسئلة كعم يبحث الكتاب وما معناه ولماذا يكون الشيئ مهما وغيرها، حتى يشغل باله البحث عن

$$
\text { ع. أجوبها التى ستظهر عند القراءة المواد العميقة. }
$$

بإحضار التركيز الموجه للمرة الثانية يبدأ القارئ قراءة كل سطر باستعمال الأصابع مشيرا إليه. ليسرع القارئ قراءته أسرع من القراءة العادية بإسراع حركة الأصابع والنظر. وكلما ازدادت سرعة حركة الأصابع على الصفحة ازدادت سرعة القراءة. وذلك لأن لا يعيد القارئ قراءة كلمة أو جملة لضياع مكان قراءته. كثير من القراء يقرأ كلمة بعد كلمة، مع أن المخ الأيسر يتركز في الأجزاء. وغاية ق القراءة السريعة أن يقرأ القارئ مجموع الكلمات بالمخ الايمن الذى يتركز في الكل. وهذا بمعنى لينظر

$$
\text { القارئ إلى كلمات معا. }
$$


ليصنح القارئ الخريطة الفكرية عما تمت قراءته، لأنه يوطد الدراسة في الذكر ويرفع مستوى الفهم عن المواد. والخريطة الفكرية ستكون مرجعا لإعادة المواد السابقة عند مواجهة الإمتحان مثلا. ومن الناحية الأخرى بعض التلاميذ ينتفعون بتحدث ما قرؤوه وذلك بأمرهم بأن يشرح بعضهم إلى بعض ما وجدوه من القراءة (De Porter, Quantum Teaching, Orchestrating

. Student Success

يمكن تدريب الطالبات بالخطوات السابقة كى يتعودن على القراءة الجيدة ويدركن المعلومات النافعة وفقا للموضوع الذى بين أيديهم. بل كانت الطريقة لكل من يهوى إلى قراءة مادة

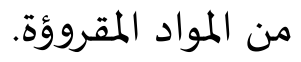

\section{إجرءات تطبيق طريقة القراءة السريعة ومناقشتها}

يمكن الإستنتاج من التعبير السابق أن تطبيق القراءة السريعة في تعليم مهارة القراءة يناسب بأساليب القراءة الجيدة، هي (De Porter, Quantum Learning, Unleashing The Genius In You):

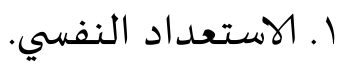
r. إزالة التشوش.

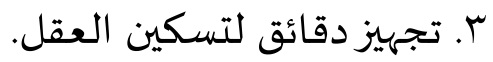
ع. استعمال أصابع أو آلة إشارة غيرها. إن العين يتبع ما يتحرك، ومن المساعدة عليه أن يتبع آلة الإشارة المتحركة من سطر بعد سطر إلى أسفل الصفحة. 0. النظر قليلا إلى المقروء قبل القراءة. هذا النظر كالمشترى الذى ينظر إلى البضائع التى يريد شرائها في المعرض أو الدكان أو السوق قبل قيامه بالبيعة. ليتعمل القارئ على المحتويات وعناوين أبواب والحروف الغليظة المائلة والخطوط البيانية والصهور وما إلى ذلك. وهذه النقطة يراد بها رفح الفهم وتقوية الذكروالراء الرئيسية من القراءة.

وأما المشكلة التى تواجهها الطالبات في تعليم مهارة القراءة هي عدم قدرة الطالبات وكفائهن في إجابة الأسئلة وصعوبة في فهم مادة قراءة اللغة العربية. ذلك لأهن يعتمدن نظام حفظ المادة بعدم فهم المادة، ويمكن الحلول على هذه المشكلة بعوامل الأساسية لزيادة سرعة القراءة فهي: 
1. أن يتأكد القارئ من سلامة نظره

من المهم قبل المباشرة في القراءة السريعة وفى القراءة عموما أن يجري الإنسان فحصيا لقوة أبصاره وصحة عينيه، خصوصا إن كان ممن يشعرون بأذى فى العين عند القراءة أو بصداع في الرأس، كذالك يكون هذا الأمر مهما لمن يرتدون نظارات طبية أو عدسات لاصقة للنظر، حيث يجب على هؤلاء إجراء فحص العين بشكل دوري. r. أن لا يقرأ القارئ بصوت مرتفع

يجب على القارئ أن يتخلص من عادة القراءة بإخراج الصهوت جهرا كان أو همسا، بل إن القراءة من خلال الصوت الداخلي، أي القراءة بصوت غير مسموع، يمكن للقارئ أن يتخلص منها بالتمرن والممارسة، ليصل إلى درجة التمكن من القراءة بمجرد النظرودون أي صهوت خارجيا كان

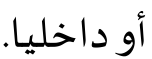
r. أن يستخدم القارئ الدليل البصري يمكن للقارئ أن يتخلص من مشكلة التراجع بالعين باستخدام دليل بصري يمر باه تحت

$$
\text { ع. أن يوسع القارئ مجال نظره ويمنع عينه التراجع . }
$$

ليوسع القارئ مجال نظره وهو ينظر إلى الكلمات والسطور. ويحاول أن ينظر إلى كلمة في

هذه الصفحة ويركز عليها حتى يجد أنه لا يراها لوحدها في الغالب، وإنما يراها وكلمة بعدها بل كلمتين أو ثلاث كلمات أو أكثر منها، هذه هو مجال النظر. يمكن للممارس أن يتمرن على أن يوسع مجال نظره حتى يستطيع بنظرة واحدة أن يفهم عدة كلمات، وهكذا يتخلص من العادة السيئة للقراءة كلمة كلمة كم تعلم في المرحلة الدراسية الأولى واستمر بممارستها عند الكبر.

$$
\text { 0. أن يعيش القارئ مع المؤلف وأفكاره }
$$

على القارئ أن يعيش في عالم الكتاب مع المؤلف وأفكاره وشخصياته وأن ينعزل عما حوله من مؤثرات، وكلما انصرف عن الشواغل الخارجية وعوارض الأفكار ازداد استغراقه في عالم

$$
\text { الكتاب وازدادت سرعته. }
$$

7. أن لا يتقيد القارئ بسرعة معينة 
وعلى الرغم من أن أساليب القراءة السريعة تهدف بداهة إلى زيادة سرعة القراءة، فإن ذلك لا يعنى أن يكون القارئ منطلقا بذات السرعة في كل ما يقرأ. بل إن قواعد القراءة السريعة يجب ألا يصبح للقارئ سرعة ثابتة في كل أنواع مواد القراءة، بل يجب أن ينوع سرعته بحسب هدفه من القراءة وبحسب نوع المادة المقروءة (العبدلي).

$$
\text { وكان طونى بوزان فى ذكر سبع النواحى من القراءة، (Herwono) هي: }
$$
ا. التعارف، عند القراءة قام القارئ بالتعارف مع الرموز الموجودة في الكتاب. والرموز في الكتاب لفئ لم تكن من الحروف بل قد تكون من الصهور الواضحة وعلامات القراءة التى لها معانى خاصة. r. الإذابة، بعد التعارف مع الرموز فى القراءة وصل القارئ إلى التكيف بدخول ما في الكتاب من المعانى والتوصيات إلى العالم الفكري. r. الإيصال الداخلى، هو البحث أو التحليل عن ارتباط البعض إلى بعض، عن الجمل والأخرى وعن المادة والمادة الأخرى ثم المقارنة بما لدى القارئ من التجربة. ع. الإيصال الخارجي، هو أخذ القرار، أيوافق القارئ مراد المقروء أم لا، وذلك عن طريق التحليل والتقدير والتشكيل والإنتقادات.

هـ الإحتفاظ، وهذا أهم نقطة من القراءة وهو يستغرق وقتا طويلا وتكريرا لازما. 7. الإعادة، هي إعادة المواد القرائية بعد أن مضت فترة من الزمان، قد يحتاج القارئ إلى ذكرها عند الامتحان مثلا أو عند مواجهة أي مشكلة. V. الحوار أو المواصلات، إن قراءة الكتاب شكل من الأشكال المواصلات. والحوار يجرى إما داخليا بين القارئ ونفسه وإما خارجيا بين القارئ وغيره من الأشخاص المذكورين والأفكار التى جائوا بها. للوصول إلى النواحى السبع المذكورة يحتاج القارئ قبل القراءة إلى إجابة السؤال الذى طرحه

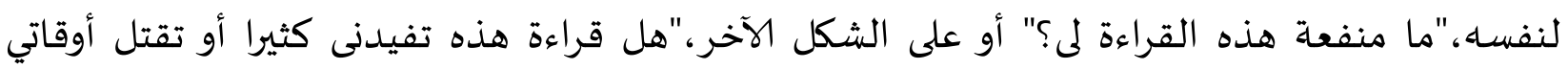

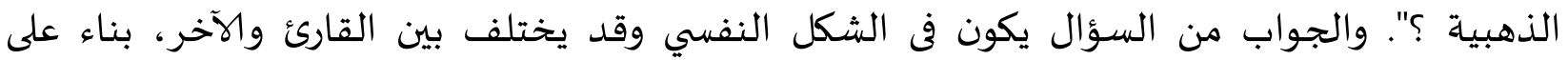
الخلفية والبيئة المحيطة باه. وتعيين الجواب نفسيا يكون حماسة قوية ودفاعا متينا للقراءة. والنواحى السبع المذكورة تناسب بخطوات تطبيق طريقة القراءة السريعة في تعليم مهارة القراءة بمعهد دار الأبرار 
من التعبير السابق تأخذ الباحثة النتيجة هي: أن تطبيق القراءة السريعة في تعليم مهارة القراءة صف الحادى عشر للبنات بمعهد دار الأبرار بونى جيد جدا لأن الطالبات يستطعن على فهم نص القراءة بسرعة ويزداد حهن في القراءة، باتباع الشروط المذكورة في خطوات تطبيق القراءة السريعة. بناءا على نتائج البحث، فتقدم الباحثة بعض التوصيات فيما يلي: ينبغي لمدرسي اللغة العربية خصيوصا في درس القراءة في المدرسة العالية بمعهد دار الأبرار أن يرقوا تطبيق طريقة القراءة السريعة ولا ينتهجوا بمثل تطبيق هذه الطريقة فحسب بل يوافقونه مع الأحوال الدراسية. وترجو من الباحثة أن ترقي وتقوي نتائج هذا البحث قياما بدراسة الطرق الأخرى التي تؤثر كذلك في رفع مهارة القراءة التي حصلت عليها الطالبات.

\section{Bibliography}

De Porter, Bobbi. Quantum Learning, Unleashing The Genius In You. Translated by Alwiyah Abdurrahman, Kaifa, 2002.

---. Quantum Teaching, Orchestrating Student Success. Translated by Nilandari, 4th ed., Kaifa, 2002.

Herwono. Quantum Reading. Cara Cepat Nan Bermanfaat Untuk Merangsang Munculnya Potensi Membaca. 4th ed., MLC, 2005.

$$
\begin{aligned}
& \text { إفندى. خريطة تعليم اللغة العربية فى اندونيسيا، لغتها وفنها. الدورة الخاصاة, ا . ب. } \\
& \text { الجربوع، سليمان. تعليم اللغنة العببية للناطقين بغيرها. جامعة أم القرى, م . ب؟. }
\end{aligned}
$$

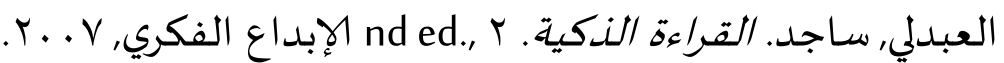

$$
\begin{aligned}
& \text { الفوزان، عبد الرحمن. العببية بين يديك الجزء الثالث. العربية للجميع, V. . Y. } \\
& \text { زين الدين، رضية. طرق واستراتجية تعليم اللغة العببية. فستاكا, 0. . ب. }
\end{aligned}
$$

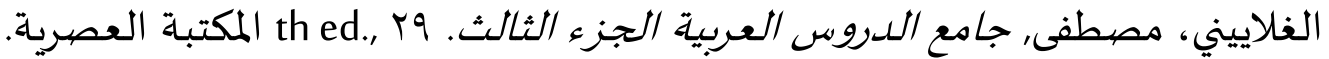

Mardhiana Jamal

تطبيق طريقة القراءة السربعة في تعليم مهارة القراءة صف الحادى

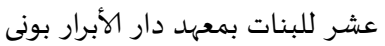

ALSUNA Vol. 1 (1), 2018 


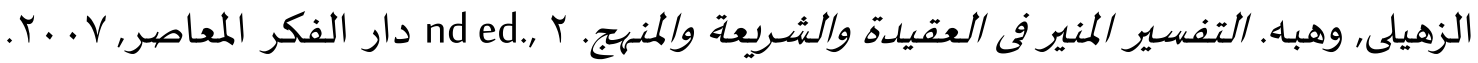
.--التفسير الوسيط للزهيلى. دار الفكر, I. . . .

Mardhiana Jamal

تطبيق طريقة القراءة السريعة في تعليم مهارة القراءة صف الحادى عشر للبنات بمعهد دار الأبرار بونى في نئي 